Байкальский государственный университет, 2. Чита, Российская Федерация

Н. Я. Кривоносова

Байкальский государственный университет, 2. Чита, Российкая Федераиия

\title{
ЛЕГАЛИЗАЦИЯ НАЛОГОВОЙ БАЗЫ: НАЛОГОВО-БЮДЖЕТНЫЙ АСПЕКТ
}

\begin{abstract}
АНнотАция. В настоящее время как в Российской Федерации в целом, так и в субъектах РФ, а также в муниципалитетах остро стоит вопрос о наполняемости бюджетов. Одним из источников доходов бюджета может стать расширение налоговой базы, в частности ее легализация. Анализ современной отечественной научной литературы показал скудность исследования понятия «легализация налоговой базы», что не дает в полном объеме воспользоваться возможным эффектом от процесса ее использования. В статье рассматривается происхождение понятия «легализация налоговой базы», обобщена зарубежная практика по легализации налоговой базы на примере Германии и Великобритании. Особое внимание уделено опыту разработки, обсуждения и принятия закона «О легализации налоговой базы» в Забайкальском крае. Определены цели и задачи комиссий налоговых органов по легализации налоговой базы. Предложена формулировка основных параметров понятия «легализация налоговой базы» с позиции государственных и муниципальных финансов. ключЕвыЕ словА. Налоговая база; легализация; налоговые органы; бюджет; увеличение доходов бюджета.

ИНФОРМАЦИЯ О СТАТЬЕ. Дата поступления 5 февраля 2016 г.; дата принятия к печати 3 апреля 2016 г.; дата онлайн-размещения 31 мая 2016 г.
\end{abstract}

\author{
O. V. Baturina \\ Baikal State University, \\ Chita, Russian Federation \\ N. Ya. Krivonosova \\ Baikal State University, \\ Chita, Russian Federation
}

\section{LEGALIZATION OF THE TAX BASE: TAX AND BUDGET ASPECT}

ABSTRACT. At the present time, both in the Russian Federation on the whole and in the $\mathrm{RF}$ entities, as well as in the municipalities there arises a topical issue of the budget fill rate. One of the budget revenue sources can result from expansion of the tax base, in particular, its legalization. An analysis of the modern domestic scientific literature has shown the poorness of research in term of the concept «legalization of the tax base», which gives no opportunity to make use of a full scale the possible effect of the process of its application. The article considers the origin of the concept «legalization of the tax base», generalizes the foreign practice of legalization of the tax base in terms of Germany and Great Britain. A special attention is given to the experience of development, discussion and adoption of the law «On Legalization of the Tax Base» in Zabaikalsky Krai. It specifies the objectives and tasks of tax authority commissions in legalizing the tax base. It offers the wording of the main parameters of the concept «legalization of the tax base» from the prospective of governmental and municipal finance.

KEYWORDS. Tax base; legalization; tax authorities; budget; increase in fiscal revenue. ARTICLE INFO. Received February 5, 2016; accepted April 3, 2016; available online May 31, 2016.

\section{Baikal Research Journal}


В современных условиях продолжающегося финансового кризиса и значительной несбалансированности бюджетов бюджетной системы РФ особенно актуальными становятся вопросы легализации налоговой базы и налоговой оптимизации. При этом наиболее ярко проявляется конфликт интересов двух сторон - налоговых органов, как представителя управленческих структур, реализующих фискальную функцию государства, и бизнес-сообщества, стремящегося уменьшить налоговое бремя.

Налоговая оптимизация как экономическая категория является предметом исследования многих специалистов, занимающихся вопросами финансового менеджмента на предприятии. $K$ числу исследователей вопроса разграничения сущности понятий «налоговая оптимизация», «налоговое планирование», «уклонение от уплаты налогов», «минимизация налогов» можно отнести таких авторов, как А. В. Брызгалин [1, с. 5], Ю. М. Лермонтов [2, с. 6], М. О. Климова [3, с. 4]. Однако вопросы легализации налоговой базы с позиции государственных и муниципальных финансов исследованы к данному моменту крайне слабо. Чаще всего это понятие с теоретической точки зрения используется в трактовке инструмента или метода повышения доходов соответствующих бюджетов. Вместе с тем анализ практики управленческой деятельности показывает, что на протяжении последних лет в каждом муниципальном образовании, субъекте РФ создаются и успешно работают межведомственные комиссии по легализации налоговой базы.

В связи с этим особый интерес представляет теоретическое исследование этимологических основ и сущности понятия «легализация налоговой базы», а также сравнение российской практики и опыта зарубежных стран по легализации налоговой базы. Для этого рассмотрим основные составляющие данного понятия в анализируемой предметной области.

Слово «легализация» происходит от лат. legalis - относящийся к законам, законный. Современные словари и справочники, как правило, опираясь на лат. legalis, параллельно приводят интерпретацию слов «легальный», «легализация», «легализировать». Проанализируем современные определения данного понятия, например, А. Б. Борисов, Б. А. Райзберг трактуют легализацию как придание юридической силы, разрешение деятельности организации [4, с. 227 ; 5, с. 202]. Л. П. Крысин определяет легализацию как переход на законное положение, придание чему-нибудь законной силы [6, с. 429]. А. Н. Ельцов рассматривает легализацию более развернуто и пишет о том, что легализация - это законная деятельность уполномоченных органов государственной власти, которая направлена на подтверждение подлинности печатей и подписей должностных лиц на имеющихся документах и их соответствие требованиям закона страны их происхождения [7, с. 199].

Таким образом, анализ показал, что этимологически понятие «легализация» имеет правовую «родословную» и является юридическим термином. Вместе с тем, отдельные авторы утверждают, что понятие «легализация» уместно лишь в увязке со словами "капитал», «имущество», «доход» [8, с. 17], что с точки зрения налогообложения может считаться налоговой базой. В связи с этим рассмотрим развитие представлений о содержании термина «налоговая база».

В широком смысле налоговую базу трактует М. Р. Пинская как объединение налогоплательщиков и объектов налогообложения конкретной территории за определенный период времени [9, с. 26]. В. В. Петровский, с одной стороны, рассматривает налоговую базу, как стоимость объектов налогообложения, представленных имуществом, доходами, оборотами по реализации, с другой стороны, как совокупность юридических и физических лиц, которые находятся в регионе, имеют доход и собственность, перечисляют налоги и обеспечивают развитие данной территории $[10$, c. 9]. Р. В. Лавник описывает налоговую базу (как государства, так и конкретного региона) как объединение налоговых баз по всем налогам и сборам в рамках

\section{Baikal Research Journal}


действующего законодательства о налогах и сборах [11, с. 8]. О. Г. Лапина определяет налоговую базу как некую совокупность определенных взаимосвязей (финансовых, производственных, коммерческих) между субъектами экономики, которая создает некоторый объект налогообложения (доход, имущественный объект, капитал и т. д.) [12, с. 35]. Если говорить о налоговой базе в узком смысле, то все определения близки к определению налоговой базы, которое приведено в п. 1 ст. 53 Налогового кодекса РФ. Так, С. Н. Андрющенко налоговую базу представляет как определенную стоимостную величину, к которой применяется ставка, установленная по этому налогу [13, с. 11]. У М. Р. Пинской налоговая база (в узком смысле) это величина, которая берется в основу при исчислении суммы налога [14, с. 126].

Таким образом, обобщая представления о понятиях «легализация» и «налоговая база», некоторыми специалистами дается толкование данного термина. Так, А. В. Толкушкин определяет легализацию налоговой базы как подтверждение подлинности, узаконения, придания юридической силы какому-либо акту или подтверждение предмета налогообложения либо показателя (показателей), принимаемых в соответствии с Налоговым кодексом РФ в качестве налоговой базы того или иного налога [15, с. 315].

Отдельные попытки введения понятия «легализация налоговой базы» предпринимаются также органами исполнительной и представительной власти. Так, проектом закона Забайкальского края «О легализации налоговой базы» предлагалась следующая его трактовка: «действия, направленные на увеличение поступлений налогов в бюджетную систему РФ путем побуждения налогоплательщиков (налоговых агентов) к обеспечению достоверности налоговой и бухгалтерской отчетности». Таким образом, основой данного законопроекта Забайкальского края было решение одной из стратегических задач любого бюджета бюджетной системы РФ - повышение его доходов, однако в качестве направления действий было выбрано лишь поощрение лиц, оказавших содействие в выявлении и (или) пресечении налоговых нарушений. Законопроектом было предусмотрено, что лицам, оказавшим содействие в выявлении и (или) пресечении налоговых правонарушений, из средств бюджета Забайкальского края должно выплачиваться денежное вознаграждение. Размер денежного вознаграждения согласно законопроекту должен был устанавливаться в процентном отношении от суммы фактически поступивших в бюджет Забайкальского края начисленных (доначисленных) в результате оказания содействия в выявлении и (или) пресечении налоговых нарушений (рис. 1).

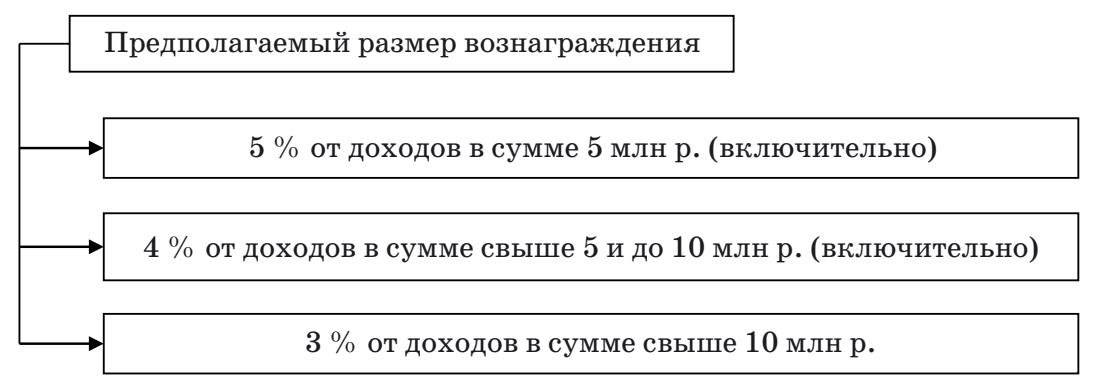

Рис. 1. Предполагаемый размер вознаграждения

Принимая во внимание данные предложения законодателей, возникает ряд вопросов, ответы на которые не предусмотрены предложенным законопроектом:

- почему вознаграждение может выплачиваться только по доходам, полученным (доначисленным) только в региональный бюджет, ведь, как правило, по результатам камеральных и выездных налоговых проверок доначисление и дополнительное

\section{Baikal Research Journal}


взыскание осуществляется по всем налогам и специальным налоговым режимам, зачисляемым во все бюджеты бюджетной системы РФ;

- какова методика, каков объем и на основании какой статьи (подстатьи) бюджетной классификации будут предусмотрены такие средства для покрытия расходов из бюджета края на выплату вознаграждений.

Учитывая все эти неточности и разногласия, выявленные в процессе обсуждения органов государственной власти с представителями научной среды, общественностью и предпринимателями, законодателями Забайкалья был отклонен данный законопроект. Таким образом, попытку внедрения специального закона о легализации налоговой базы в Забайкалье можно назвать неудачной. Тем не менее, практика управленческой деятельности показывает, что в арсенале налоговых органов для выполнения фискальной функции имеется ставший уже традиционным инструмент - комиссии налоговых органов по легализации налоговой базы. Работа указанных комиссий регламентируется Письмом Федеральной налоговой службы России «О работе комиссий налоговых органов по легализации налоговой базы» от 17 июля 2013 г. № AC-4-2/12722.

На сегодняшний день сложилась достаточно успешная практика в деятельности таких межведомственных комиссий (рис. 2). Многие межрайонные инспекции Федеральной налоговой службы России, отдельные муниципальные образования ежеквартально публикуют статистическую отчетность и результаты деятельности таких межведомственных комиссий. Вместе с тем единой информационной базы с результатами деятельности таких комиссий к настоящему времени в рамках деятельности управлений Федеральной налоговой службы России не выявлено. Кроме того, несмотря на достаточно полные рекомендации по организации деятельности комиссий, представленные в указанном документе, сложностью является отсутствие единого алгоритма в рамках деятельности таких комиссий.

Тем не менее, отдельными авторами, такими как Ф. Ф. Ханафеев и А. Ф. Ханафеев, предпринимаются попытки систематизации отдельных этапов деятельности комиссий по легализации налоговой базы в соответствии с действующим законодательством [16, с. 26].

Следует подчеркнуть, что в работе комиссий по легализации налоговой базы значительное место должно быть отведено аналитической работе, при этом в качестве источников информации и основанием для вызова на комиссию могут служить не только данные статистической и финансовой отчетности, но и информация, содержащаяся в средствах массовой информации, сети Интернет; сведения, полученные от кредитных организаций, правоохранительных органов, Пенсионного фонда РФ и других внебюджетных фондов, лицензирующих органов, таможенных органов, других государственных и муниципальных органов власти, Банка России; жалобы, заявления юридических и физических лиц; информация, полученная от сотрудников, акционеров (участников) организаций.

Особое внимание следует уделять структурным характеристикам и формам уклонения от уплаты налогов, выделенным А. П. Киреенко - это занижению объектов налогообложения; завышению затрат (льгот, вычетов); задержке в перечислении налоговых платежей [17, с. 165]. При этом наиболее тщательно должны быть рассмотрены основные элементы бухгалтерской управленческой отчетности (активы, обязательства, капитал, доходы и расходы организации, трудовые ресурсы и другие элементы), систематизированные И. А. Слободняком [18, с. 18-19].

Особую роль в деятельности таких комиссий должно играть и профессиональное суждение участников таких комиссий, которые в своей деятельности должны руководствоваться рядом принципов, предложенных И. А. Слободняком:

- системный подход;

\section{Baikal Research Journal}

электронный научный журнал Байкальского государственного университета 
- обоснованность;

- последовательность;

- однозначность;

- возможность технической реализации;

- приоритет содержания над формой;

- периодический контроль [19, с. 32].

Организация работы комиссий налоговых органов по легализации налоговой базы

\begin{tabular}{|l|}
\hline \multicolumn{1}{|l|}{ Цель работы комиссии: увеличение поступлений налогов в бюджет } \\
\hline \\
Инструменты: побуждение налогоплательщиков самостоятельно уточнить \\
налоговую базу
\end{tabular}

Предмет рассмотрения: вопросы правильности формирования налоговой базы и полноты уплаты налогоплательщиками (налоговыми агентами) следующих налогов: - налог на добавленную стоимость; - налог на имущество физических лиц; - налог на прибыль организаций; - земельный налог;

- налог на доходы физических лиц;

- налог на имущество организаций;

- транспортный налог;

- единый сельскохозяйственный налог и единый налог на вмененный доход;

- единый налог, уплачиваемый при применении упрощенной системы налогообложения

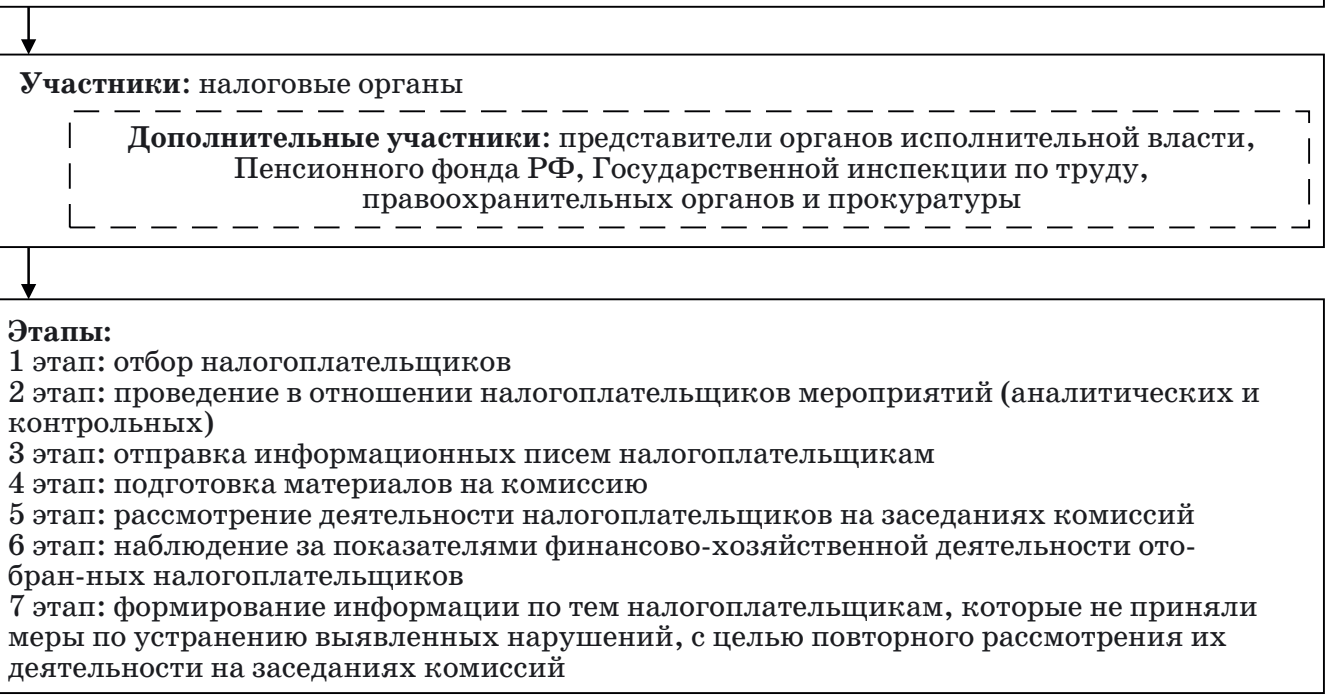

Рис. 2. Организация работы колиссий налоговых органов по легализации налоговой базы

Кроме того, в рамках аналитической работы следует уделить внимание и анализу деятельности самих комиссий по легализации налоговой базы. Для этого может быть использован показатель уровня издержек налогового администрирования, предложенный А. П. Киреенко и С. С. Быковым [20, с. 73], показывающий насколь-

\section{Baikal Research Journal}


ко велики затраты на работу межведомственных комиссий по сравнению с величиной дополнительных доходов, доначисленных и полученных в бюджеты в результате деятельности таких комиссий.

Зарубежная практика по легализации налоговой базы с позиции государственных и муниципальных финансов имеет существенные различия по сравнению с российским опытом. Так, в регулировании британского налогообложения важнейшую роль играют суды. Степень добросовестности налогоплательщиков определяют только суды. Именно суды изучают суть сделки и решают, была ли у них иная цель, кроме уклонения от налогов [21, с. 15]. например, в деле IRC v Duke of Westminster (1936) говорится о том, что любой человек может осуществлять свою деятельность таким образом, при котором налоги, которые он уплатит в бюджет, могут быть меньше, чем могли бы быть в ином случае. Если налогоплательщик смог добиться уплаты налогов совершенно законным способом, то его «умение» будет отрицательно расценено Службой внутренних доходов Великобритании и, возможно, другими налогоплательщиками, но никто не может его заставить платить увеличенную сумму налога.

Суды Великобритании при рассмотрении дел о легализации налоговой базы зачастую пользуются следующими суждениями [22, с. 117] в данном правовом вопросе:

- «отсутствие коммерческой цели» - если деятельность налогоплательщика нацелена только на оптимизацию (минимизацию) налогообложения, а не на получение дохода (прибыли), то она может быть признана незаконной;

- «связанность отдельных этапов» - любая деятельность (сделка) налогоплательщика реализуется поэтапно, поэтому каждый этап может быть рассмотрен отдельно как часть всей сделки;

- «приоритет содержания перед формой» - основное внимание следует уделять содержанию сделки, а меньшее на ее форму.

В Великобритании распространена процедура предоставления информации налоговому органу о применяемых налогоплательщиком схемах оптимизации налогообложения, которая была введена и утверждена в 2004 г. Для этого была образована Группа по борьбе с уклонением от уплаты налогов Службы таможенных и налоговых платежей Великобритании (Anti-Avoidance Group of the Customs and Revenue Service) ${ }^{1}$. Цель - снижение рисков как государства, так и налогоплательщика. В случае, если налогоплательщик полностью открывает информацию об используемой схеме, то налоговый орган формирует ответ на запрос о законности (незаконности) рассматриваемой схемы. Если схема безопасна, то в письме налогового органа будет официальное подтверждение того, что никаких разбирательств, по указанной схеме, со стороны налогового органа не будет. Однако обязательным требованием законодательства о налогах Великобритании является следующий постулат: все пользователи схем по оптимизации налогообложения доходов физических лиц, доходов от прироста капитала и доходов юридических лиц должны предоставлять информацию обо всех оговоренных случаях в указанный орган контроля.

В Германии в структуре налоговой администрации имеются специальные следственные органы, которые наделены законными полномочиями для расследования и преследования уклонения от уплаты налогов и пресечения, направленных на это попыток. В частности, за последние 5-6 лет в уголовном процессе часто использовалась компрометирующая информация, записанная на компакт-дисках, «закупленных» у третьих лиц, которые создавали или обретали эти диски нелегальным путем. Эта информация помимо личных данных содержала сведения об учетных записях на счетах налогоплательщиков-резидентов (вкладов, банковских операциях, процентах и т. д.) в зарубежных банках.

${ }^{1}$ HM Revenue \& Customs. URL : http://www.hmrc.gov.uk/avoidance/index.htm.

\section{Baikal Research Journal}

электронный научный журнал Байкальского государственного университета 
Вопрос о том, правомерно ли использовать подобным путем информацию с целью налогообложения, занимает немецкую общественность, а также множество тех самых лиц, которые подозреваются в уклонении от уплаты налогов. Тем не менее, финансовый суд г. Кельна решением от 15 декабря 2010 г. постановил, что использование с целью налогообложения данных о зарубежных вкладах немецких налогоплательщиков, приобретенных органами ФРГ, не противоречит закону ${ }^{2}$.

Подводя итог анализа английской и немецкой практики по легализации налоговой базы, установлены следующие моменты:

- принято решение на государственном уровне о возможности и необходимости раскрытия источников легализации налоговой базы;

- обозначены меры дополнительного налогового контроля в данной сфере;

- определена обязательность контрольных процедур;

- созданы соответствующие институты, осуществляющие такую работу.

Таким образом, анализ теоретических основ и практики работы по легализации налоговой базы с позиции государственных и муниципальных финансов в России и за рубежом показал необходимость формулировки основных параметров, характеризующих с теоретической точки зрения понятие «легализация налоговой базы».

С нашей точки зрения, процесс легализации налоговой базы с позиции теории финансов затрагивает одновременно несколько сфер финансовой системы - государственные (муниципальные) финансы, финансы предприятий, а также финансы домашних хозяйств. В связи с этим, взаимозависимыми и подверженными влиянию друг на друга являются процесс легализации налоговой базы в государственном секторе и процесс налоговой оптимизации, происходящий в корпоративных финансах и финансах домохозяйств.

Основные параметры, характеризующие понятие «легализация налоговой базы», а также их взаимодействие с финансами предприятий и домохозяйств, представлены на рис. 3.

\begin{tabular}{|c|c|c|c|c|c|}
\hline \multicolumn{3}{|c|}{$\begin{array}{c}\text { Налоговая оптимизация } \\
\text { налогоплательщика - юридического лица }\end{array}$} & \multicolumn{3}{|c|}{$\begin{array}{c}\text { Налоговая оптимизация } \\
\text { налогоплательщика - физического лица }\end{array}$} \\
\hline \multicolumn{6}{|c|}{$\begin{array}{c}\text { Легализация налоговой базы (с позиции государственных и муниципальных финансов) - } \\
\text { совокупность мероприятий, проводимых субъектами легализации налоговой базы, } \\
\text { направленные на перевод на легальное положение (признание законными) основных } \\
\text { характеристик объектов легализации налоговой базы }\end{array}$} \\
\hline$\frac{1}{v}$ & $\downarrow$ & & $\frac{1}{7}$ & $\downarrow$ & $\frac{1}{2}$ \\
\hline Цель & Задачи & & Субъект & Объект & Период \\
\hline $\begin{array}{c}\text { Своевремен- } \\
\text { ное получе- } \\
\text { ние информа- } \\
\text { ции от нало- } \\
\text { гоплательщи- } \\
\text { ков о закон- } \\
\text { ности налого- } \\
\text { вой базы в } \\
\text { процессе } \\
\text { налогообло- } \\
\text { жения }\end{array}$ & $\begin{array}{c}\text { Расширение нало- } \\
\text { гового потенциала } \\
\text { территории } \\
\text { Повышение } \\
\text { доходов бюджетов } \\
\text { бюджетной } \\
\text { системы } \\
\text { Соблюдение нало- } \\
\text { говой дисциплины } \\
\text { Рост налоговой } \\
\text { культуры }\end{array}$ & $\begin{array}{r}\mathrm{O} \\
\mathrm{cтв} \\
\Pi \\
\mathrm{Ha} \\
\mathrm{B} \\
\mathrm{E} \\
\text { Ком } \\
\text { Нал }\end{array}$ & $\begin{array}{l}\text { ны государ- } \\
\text { ой и муници- } \\
\text { ьной власти } \\
\text { деральная } \\
\text { овая служба } \\
\text { бюджетные } \\
\text { фонды } \\
\text { цк России и } \\
\text { рческие банки } \\
\text { плательщики }\end{array}$ & $\begin{array}{c}\text { Стоимост- } \\
\text { ная, физи- } \\
\text { ческая или } \\
\text { иная харак- } \\
\text { теристика } \\
\text { объекта } \\
\text { налогообло- } \\
\text { жения }\end{array}$ & $\begin{array}{c}\text { Месяц } \\
\text { Квартал } \\
\text { Полугодие } \\
\text { Год (макси- } \\
\text { мальный } \\
\text { период - } \\
\text { три года) }\end{array}$ \\
\hline
\end{tabular}

Рис. 3. Основные параметры понятия «легализаиия налоговой базы»

${ }^{2}$ FG Köln Beschluss vom 15.12.2010, 14 V 2484, DStrRE 2011, 1076.

\section{Baikal Research Journal}


Проведенное исследование теории и практики легализации налоговой базы с позиции государственных (муниципальных) финансов в России и за рубежом позволило решить ряд задач:

- рассмотрены этимологические основы происхождения понятия «легализация налоговой базы»;

- собрана и проанализирована практика по легализации налоговой базы в России, Великобритании и Германии;

- представлен опыт разработки, обсуждения и внедрения специального закона «О легализации налоговой базы» на региональном уровне;

- обоснована необходимость и сделана попытка формулировки основных параметров понятия «легализация налоговой базы» с позиции государственных (муниципальных финансов).

Таким образом, решение перечисленных задач может послужить основой для дальнейших научных разработок в данной предметной области и будет способствовать совершенствованию управления государственными финансами на региональном и муниципальном уровнях власти.

\section{Список использованной литературы}

1. Брызгалин А. В. Налоговая оптимизация: принципы, методы, рекомендации, арбитражная практика / А. В. Брызгалин, В. Р. Берник, А Н. Головкин. - М. : Юрайт, 2006. $-302 \mathrm{c}$.

2. Лермонтов Ю. М. Оптимизация налогообложения: рекомендации по исчислению и уплате налогов / Ю. М. Лермонтов. - М. : Налог. вестник, 2008. - 352 с.

3. Климова М. О. К вопросу о проблеме идентификации уклонения от уплаты налогов [Электронный ресурс] / М. О. Климова // Известия Иркутской государственной экономической академии (Байкальский государственный университет экономики и права). -2013. № 1. - Режим доступа : http://brj-bguep.ru/reader/article.aspx?id=18673.

4. Борисов А. Б. Большой экономический словарь / А. Б. Борисов. - М. : Кн. мир, 2006. $-543 \mathrm{c}$.

5. Райзберг Б. А. Современный экономический словарь / Б. А. Райзерберг, Л. Ш. Лозовский, Е. Б. Стародубцева. - 4-е изд., перераб. и доп. - М. : Инфра-М, 2005. - 480 с.

6. Крысин Л. П. Толковый словарь иноязычных слов / Л. П. Крысин. - М. : Эксмо, 2006. - 944 с. - (Библиотека словарей).

7. Ельцов А. Н. Легализация документов: проблемы терминологического определения и сущности / А. Н. Ельцов // Вестник Тамбовского университета. Сер.: Гуманитарные науки. -2009 . - № 2 (70). - С. 195-200.

8. Бодров В. А. Уголовно-правовые и криминологические проблемы борьбы с легализацией преступных доходов : дис. ... канд. юрид. наук : 12.00 .08 / В. А. Бодров. - М., 2008. - 183 с.

9. Пинская М. Р. Налоговая база территории: конкуренция и меры по расширению / М. Р. Пинская // Налоговая политика и практика. - 2011. - № 8. - С. 26-30.

10. Петровский В. В. Управление развитием региональных налоговых баз : автореф. дис... канд. экон. наук : 08.00.05 / В. В. Петровский. - Рыбинск, 2006. -23 с.

11. Лавник Р. В. Совершенствование налоговой базы региона (на примере субъектов ЦФО) : автореф. дис... канд. экон. наук : 08.00.10 / Р. В. Лавник. - М., 2010. - 31 с.

12. Лапина О. Г. Расчет налоговой базы переходного периода / О. Г. Лапина. - М. : Междунар. центр финансово-экон. развития, 2002. - $176 \mathrm{c.}$

13. Андрющенко С. Н. Пути расширения региональной налоговой базы в рыночной экономике современной России : автореф. дис. ... канд. экон. наук : 08.00.10 / С. Н. Андрющенко. - M., 2004. - $21 \mathrm{c}$.

14. Пинская М. Р. Основы теории налогов и налогообложения : монография / М. Р. Пинская ; под науч. ред. В. С. Барда. - М. : Палеотип, 2004. - 216 с.

15. Толкушкин А. В. Энциклопедия российского и международного налогообложения / А. В. Толкушкин. - М. : Юристъ, 2003. - 910 с.

16. Ханафеев Ф. Ф. Противодействие легализации (отмыванию) доходов, полученных преступным путем, как направление обеспечения экономической безопасности государ-

\section{Baikal Research Journal}


ства / Ф. Ф. Ханафеев, А. Ф. Ханафеев // Инновационное развитие экономики. - 2014. № 2 (19). - С. 24-30.

17. Киреенко А. П. Различие и взаимосвязь теневой экономики и уклонения от уплаты налогов / А. П. Киреенко // Налоги и финансовое право. - 2012. — № 9. - С. 164-171.

18. Слободняк И. А. Система учетно-аналитической информации бухгалтерской управленческой отчетности коммерческой организации / И. А. Слободняк. - Иркутск : Изд-во БГУЭП, 2011. - 261 с.

19. Слободняк И. А. Исследование профессионального суждения при формировании учетно-аналитической информации о доходах организации для бухгалтерской управленческой отчетности / И. А. Слободняк // Международный бухгалтерский учет. - 2011. — № 27. С. $31-41$.

20. Киреенко А. П. Издержки налогообложения в Российской Федерации / А. П. Киреенко, С. С. Быков. - Иркутск : Изд-во БГУЭП, 2012. -190 с.

21. Мижинский М. Ю. Борьба с уклонением от уплаты налогов: правовой опыт Великобритании / М. Ю. Мижинский // Финансовое право. - 2006. — № 5. — С. 13-18.

22. Salter David, Lee Natalie, Shape John. Revenue Law. Text and Materials. - Tottel Publishing, 2007. -726 p.

\section{References}

1. Bryzgalin A. V., Bernik V. R., Golovkin A N. Nalogovaya optimizatsiya: printsipy, meto$d y$, rekomendatsii, arbitrazhnaya praktika [Tax optimization: principles, methods, recommendations, arbitration practice]. Moscow, Yurait Publ., 2006. 302 p.

2. Lermontov Yu. M. Optimizatsiya nalogooblozheniya: rekomendatsii po ischisleniyu $i$ uplate nalogov [Optimization of taxation: recommendations on tax calculation and payment]. Moscow, Nalogovyi vestnik Publ., 2008. 352 p.

3. Klimova M. O. On problem of identifying tax avoidance. Izvestiya Irkutskoy gosudarstvennoy ekonomicheskoy akademii (Baykalskiy gosudarstvennyy universitet ekonomiki i prava) = Bulletin of Irkutsk State Economics Academy (Baikal State University of Economics and Law), 2013, no. 1. Available at: http://brj-bguep.ru/reader/article.aspx?id=18673. (In Russian).

4. Borisov A. B. Bol'shoi ekonomicheskii slovar' [The Large Economic Dictionary]. Moscow, Knizhnyi mir Publ., 2006. 543 p.

5. Raizberg B. A., Lozovskii L. Sh., Starodubtseva E. B. Sovremennyi ekonomicheskii slovar' [The Modern Economic Dictionary]. 4th ed. Moscow, Infra-M Publ., 2005. 480 p.

6. Krysin L. P. Tolkovyi slovar' inoyazychnykh slov [The Definition Dictionary of Foreign Words]. Moscow, Eksmo Publ., 2006. 944 p.

7. Eltsov A. N. Documentary legalization: problems of terminological definition and essence. Vestnik Tambovskogo universiteta. Seriya: Gumanitarnye nauki = Tambov University Review. Series: Humanities, 2009, no. 2 (70), pp. 195-200. (In Russian).

8. Bodrov V. A. Ugolovno-pravovye i kriminologicheskie problemy bor'by s legalizatsiei prestupnykh dokhodov. Kand. Diss. [Criminal-legal and criminological problems of protection from criminal revenue legalization. Cand. Diss.]. Moscow, 2008. $183 \mathrm{p}$.

9. Pinskaya M. R. Territorial tax base: competition and expansion measures. Nalogovaya politika i praktika = Tax policy and practice, 2011, no. 8, pp. 26-30. (In Russian).

10. Petrovskii V. V. Upravlenie razvitiem regional'nykh nalogovykh baz. Avtoref. Kand. Diss. [Development management for regional tax base. Cand. Diss. Thesis]. Rybinsk, 2006. 23 p.

11. Lavnik R. V. Sovershenstvovanie nalogovoi bazy regiona (na primere sub"ektov TsFO). Avtoref. Kand. Diss. [Improving the regional tax base (in terms of CFD entities). Cand. Diss. Thesis]. Moscow, 2010. $31 \mathrm{p}$.

12. Lapina O. G. Raschet nalogovoi bazy perekhodnogo perioda [Calculation of the tax base of the transitional period] Moscow, International Center for Finance and Economic Development Publ., 2002. $176 \mathrm{p}$.

13. Andryushchenko S. N. Puti rasshireniya regional'noi nalogovoi bazy $v$ rynochnoi ekonomike sovremennoi Rossii. Avtoref. Kand. Diss. [Ways of expanding the regional tax base in market economy of modern Russia. [Cand. Diss. Thesis]. Moscow, 2004. $21 \mathrm{p}$.

14. Pinskaya M. R.; Bard V. S. (ed.). Osnovy teorii nalogov i nalogooblozheniya [Basics of Theory of Taxes and Taxation]. Moscow, Paleotip Publ., 2004. 216 p.

\section{Baikal Research Journal}


15. Tolkushkin A. V. Entsiklopediya rossiiskogo i mezhdunarodnogo nalogooblozheniya [Encyclopedia of Russian and International Taxation]. Moscow, Yurist» Publ., 2003. 910 p.

16. Khanafeyev F. F., Khanafeyev A. F. Countering legalization (laundering) of revenue gained criminally as a direction for providing national economic security. Innovatsionnoe razvitie ekonomiki = Innovative Development of Economy, 2014, no. 2 (19), pp. 24-30. (In Russian).

17. Kireyenko A. P. Difference and interrelation of shadow economy and tax avoidance. Nalo gi i finansovoe pravo = Taxes and Financial Law, 2012, no. 9, pp. 164-171. (In Russian).

18. Slobodnyak I. A. Sistema uchetno-analiticheskoi informatsii bukhgalterskoi upravlencheskoi otchetnosti kommercheskoi organizatsii [System of accounting and analytical information for accounting managerial records in commercial organizations]. Irkutsk, Baikal State University of Economics and Law Publ., 2011. 261 p.

19. Slobodnyak I. A. Investigation of professional judgment in compiling accounting and analytical information about the company's revenue for accounting managerial records. Mezhdunarodnyi bukhgalterskii uchet = International Accounting, 2011, no. 27, pp. 31-41. (In Russian).

20. Kireyenko A. P., Bykov S. S. Izderzhki nalogooblozheniya v Rossiiskoi Federatsii [Expenses of taxation in the Russian Federation]. Irkutsk, Baikal State University of Economics and Law Publ., 2012. $190 \mathrm{p}$.

21. Mizhinsky M. Yu. Protection from tax avoidance: legal experience of Great Britain. Finansovoe pravo = Financial Law, 2006, no. 5, pp. 13-18. (In Russian).

22. Salter David, Lee Natalie, Shape John. Revenue Law. Text and Materials. Tottel Publishing, 2007. $726 \mathrm{p}$.

\section{Информация об авторах}

Батурина Ольга Викторовна - кандидат экономических наук, доцент, кафедра финансов и кредита, Читинский институт, Байкальский государственный университет, 672000, г. Чита, ул. Анохина, 56, e-mail: baturina_80@mail.ru.

Кривоносова Наталья Яковлевна - кандидат экономических наук, доцент, кафедра финансов и кредита, Читинский институт, Байкальский государственный университет, 672000, г. Чита, ул. Анохина, 56, e-mail: krivonos_nat_ja@mail.ru.

\section{Authors}

Olga V. Baturina - PhD in Economics, Associate Professor, Department of Finance and Credit, Chita Institute of Baikal State University, 56 Anokhin St., 672000, Chita, Russian Federation; e-mail: baturina_80@mail.ru.

Natalia Ya. Krivonosova - PhD in Economics, Associate Professor, Department of Finance and Credit, Chita Institute of Baikal State University, 56 Anokhin St., 672000, Chita, Russian Federation; e-mail: krivonos_nat_ja@mail.ru.

\section{Библиографическое описание статьи}

Батурина О. В. Легализация налоговой базы: налогово-бюджетный аспект / О. В. Батурина, Н. Я. Кривоносова / / Baikal Research Journal. — 2016. — T. 7, № 3. — DOI : 10.17150/2411$\underline{6262.2016 .7(3) .9}$.

\section{Reference to article}

Baturina O. V., Krivonosova N. Ya. Legalization of the tax base: tax and budget aspect. Baikal Research Journal, 2016, vol. 7, no. 3. DOI : 10.17150/2411-6262.2016.7(3).9. (In Russian).

\section{Baikal Research Journal}

